\title{
Latent Structure of the Morphological Characteristics and Motor Basic Abilities and Situational to Basketball Players 14-15 years
}

\author{
Bujar Begu', Artan R. Kryeziu² and Jeton Havolli \\ 'Universi College, Department of Physical Culture, Sport and Recreation, Prishtina, Kosovo, ${ }^{2}$ College FAMA, Faculty of Children Care and Welfare, \\ Prishtina, Kosovo
}

\begin{abstract}
The purpose of this research is Latent Structure of the morphological characteristics and motor basic abilities and situational to basketball players 14-15 years. The sample was of 84 basketball players aged 14-15 who have followed the training process of basketball game. The variable samples are 23,11 of them in morphological space, 8 tests in the area of basic motor character and 4 of them in situational motor of basketball game. In this research our experiment is extracted in two main components which explain $79.16 \%$ the general variance of the morphological system, from which are extracted two morphological elements, with this we confirmed the previous scientific knowledge that was enabled to use during the research more precisely in extracting the latent structure in the morphological area. While in the motor area are extracted three main components that explain together $63.60 \%$ the variance of the basic and situational motor system of which three factors are extracted.
\end{abstract}

Key words: structure, morphological, motor basic and situational, basketball

\section{Introduction}

Basketball is focused on the methodological approach of learning the highest level of the game as well as the rise of motor and specific movements. Some research studies have took on base the morphological characteristics and the motor space, which are specific indicators for the development of the next basketball player (Trninić, 1996; Petrov, 2011; Kryeziu \& Asllani, 2016). The game of basketball is a complex activity and task requirements which are specific skills selected for each player, depending on his position in the team, which performs certain tasks in the game of basketball (Trninić, Karalejić, Jakovljević, \& Jelaska, 2010). At the same time, morphological characteristics describe physical structure and influence the overall motor-functional and situation-related efficiency of a basketball player (Jeličić, 2006; Trninić, 2006).

The best trends in raising of basketball skills, the importance is to determine the structure factor according on tests of static force, flexibility, repetitive force, explosive force and balance. Based on numerous researches which are limited only on motor tests, it is noted that achieving success in basketball game along motor tests is needed to see off other segments of anthropological status of future players (Trninić et al., 2010; Kocić \& Antonijević, 2013). Anthropological space is inportant atribute for definition of basketball structure in motor space, particulary in preparing of basketball players for basketball game for specific actions of the basketball game (Jukić, Milanović, \&Vuleta, 2005).

The analyse of structural space on morphological characteristics, motor basic and situational testes typical of basketball game are specifically for each basketball player, because the dynamics and structure of basketball player, the development is unique in the morphological space as well as in the basic and situational motor. Characteristics of basketball players of this age treated in this research are related to the adolescence age. The present level of science knodwelege in

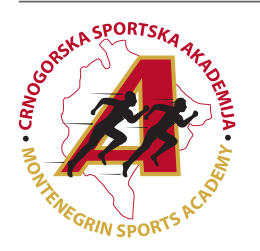

Correspondence:

B. Begu

Universi College, Department of Physical Culture, Sport and Recreation, Vilage Bardhosh, Prishtina, Kosovo

Email: bujarbegu4@gmail.com 
this area is noticed that: motor dimensions in many researches appear in certain ways with different tasks. With application of factorial analysis are revealed more and more factors which prove the existence of many motor factors as they are: strength, speed, coordination, flexibility, etc and which has led to the question how many motor dimensions objectively exist and what is the ratio between them. We may say that this research will achieve valid and important results in some basic and morphological parameters, situational motor skills of new basketball players.

The purpose of this research is latent structure of the morphological characteristics and motor basic abilities and situational to basketball players $14-15$ years.

\section{Methods}

Sample entities

This research consists active players (males) of age 1415 years old who plays in cadet's league, some of them are incorporated from pioneer's league which will play in cadet's league beside Basketball Federation of Kosovo.

Total number of entities that are tested in this research is 84 , which are divided in 7 teams with 12 players. Tested teams of Mitrovica Region are: Basketball Club BC "Mitrovica", Basketball Club BC “Trepça” from Mitrovica, and Basketball Club BC "Vushtrriabasket" from Vushtrri. While the Pristina Region are those teams: Basketball Club BC "Collage Universi“, Basketball Club BC "Fatosat", Basketball Club BC "Albabasket", and Basketball Club BC "Probasket" all those clubs from Pristina.

\section{Variable samples}

Instruments for measuring morphological variables they have treated 11 variables. Whereas, motor space with situational motor are treated 8 tests motor into basic character, and 4 of typical situational motor of basketball game.
Morphological variables: 1.Body weight; 2 . Body height; 3. Length of leg; 4. Foot length; 5. Foot width; 6. Arm circumference; 7. Thighs circumference; 8. Calf circumference; 9. Palm length; 10. Palm width with open fingers; 11. Arms length.

Basic motor and situational variables: 1 . Jump high above the place; 2 . Jump from the place with the step height; 3 . Jump length from the place; 4 . Speed running $20 \mathrm{~m}$ (higher start); 5. Throwing the medicin ball from the chest; 6. Profound warp (flexibility); 7. Abdominal muscles; 8 . T-Agile test; 9. Ball dribble between cones (zig-zag); 10. Ball dribble and shooting in $30 \mathrm{sec} ; 11$. Shooting for 2 points; 12 . Free shooting.

Measuring instruments are applied-tested according to the authors (Blasković, 1982; Erčulj, 2005; Pojskić, Šeparović, \& Užičanin, 2010; Bajgorić, Bilić, \& Bonacin, 2013).

\section{Statistical analysis}

Data were processed with SPSS statistical software programine package version 21.0 for Windows, research latent structure of space that will be explored through factor analysis.

\section{Results}

In Table 1 are presented main characteristic roots (LAMBDA) as well as their partial and cumulative contribution to the clarification of the overall variability. Characteristic roots are listed by size and are 11 of them, but valuable only by Hotteling method and the criterion GK (Gutman-Kaiser). Two main components were extracted which together account for $79.16 \%$ of the overall variance of the morphological system. The first characteristic root of system explains $56.29 \%$ of general variance. Second characteristic root explains $22.87 \%$ of general variance.

Table 1. Key characteristics and explanatory parts of the common variance in the morphological area

\begin{tabular}{cccccccc}
\hline Comp. & Total & $\begin{array}{c}\text { \% of } \\
\text { Variance }\end{array}$ & Cumul. \% & Total & $\begin{array}{c}\text { \% of } \\
\text { Variance }\end{array}$ & Cumul. \% & Total \\
\hline 1 & 6.193 & 56.298 & 56.298 & 6.193 & 56.298 & 56.298 & 5.502 \\
2 & 2.516 & 22.871 & 79.169 & 2.516 & 22.871 & 79.169 & 4.474 \\
3 & .595 & 5.411 & 84.580 & & & & \\
4 & .502 & 4.566 & 89.146 & & & \\
5 & .306 & 2.785 & 91.931 & & & \\
6 & .286 & 2.601 & 94.532 & & & \\
7 & .256 & 2.325 & 96.857 & & & \\
8 & .152 & 1.381 & 98.238 & & & \\
9 & .098 & .887 & 99.126 & & & & \\
10 & .066 & .598 & 99.724 & & & & \\
11 & .030 & .276 & 100.000 & & & & \\
\hline
\end{tabular}

In Table 2 in the first component are designed with high values in all variables that give insight into the human morphological dimensions. Second component has high projections at AARMCI-Arm circumference .669, ATHICI-Thighs circumference .721 and ACALCI-Calf circumference .629 are indicative of body mass and capacity. The value of communality for all variables ranges from .55 to .95 . Reliability for each variable depends on the size of the communality, respectively the uniqueness.
Table 3 on base of the parallel matrix projections we noticed that high projections in the first factor have realized variables: ABADHE-Body height .923, ALENGL-Length of leg .943, AFOOLE-Foot length .832, APALML-Palm length .893, APWOFI- Palm width with open fingers .747 and AARMLEArms length .908. Based on the projections in the first factor of variables, this factor can be named as: Longitudinal skeleton factor.

In the second factor the high projections have realized the 
Table 2. Main components and communality

\begin{tabular}{lccc}
\hline variable & $\mathbf{1}$ & $\mathbf{2}$ & H2 \\
\hline ABADWE & .843 & .491 & .953 \\
ABADHE & .868 & -.366 & .887 \\
ALENGL & .764 & -.490 & .823 \\
AFOOLE & .779 & -.333 & .718 \\
AFOOTW & .728 & .139 & .550 \\
AARMCI & .568 & .669 & .771 \\
ATHICI & .639 & .721 & .929 \\
ACALCI & .696 & .629 & .881 \\
APALML & .755 & -.434 & .758 \\
APWOFI & .694 & -.304 & .575 \\
AARMLE & .860 & -.354 & .866 \\
\hline
\end{tabular}

Legend: ABADWE-Body weight; ABADHE-Body height; ALENGLLength of leg; AFOOLE-Foot length; AFOOTW-Foot width; AARMCI-Arm circumference; ATHICI-Thighs circumference; ACALCI-Calf circumference; APALML-Palm length; APWOFI-Palm width with open fingers; AARMLE-Arms length

variables ABADWE-Body weight .867, AFOOTW-Foot width .472, AARMCI-Arm circumference .911, ATHICI-Thighs circumference .994, ACALCI-Calf circumference 932. Based on projections in second factor, this factor can be named as: Volume factor and body mass index.The matrix of the orthogonal projections of variables in the factor. The structure of this matrix does not differ much from the matrix of parallel projections.

Table 3. The matrix of parallel projections and orthogonal projections

\begin{tabular}{lcccc}
\hline variable & $\begin{array}{c}\text { The matrix of parallel } \\
\text { projections }\end{array}$ & \multicolumn{2}{c}{$\begin{array}{c}\text { The matrix of orthogonal } \\
\text { projections }\end{array}$} \\
& $\mathbf{1}$ & $\mathbf{2}$ & $\mathbf{1}$ & $\mathbf{2}$ \\
\hline ABADWE & .234 & .867 & .547 & .951 \\
ABADHE & .923 & .049 & .941 & .383 \\
ALENGL & .943 & -.118 & .900 & .222 \\
AFOOLE & .832 & .040 & .846 & .341 \\
AFOOTW & .426 & .472 & .596 & .626 \\
AARMCI & -.107 & .911 & .222 & .872 \\
ATHICI & -.096 & .994 & .263 & .960 \\
ACALCI & .018 & .932 & .355 & .938 \\
APALML & .893 & -.068 & .868 & .254 \\
APWOFI & .747 & .028 & .758 & .299 \\
AARMLE & .908 & .058 & .929 & .386 \\
\hline
\end{tabular}

In Table 4 intercorrelations between factors, is realized important correlation between factor 1 longitudinal of the skele-

ton and factor 2 volume and body mass.

Table 4. Intercorrelations between factors

\begin{tabular}{lcc}
\hline Comp. & Factor $\mathbf{1}$ & Factor $\mathbf{2}$ \\
\hline Factor 1 & 1.000 & \\
Factor 2 & 0.361 & 1.000 \\
\hline
\end{tabular}

Legend: Factor 1. The longitudinal of the skeleton; Factor 2. Volume and body mass

In Table 5 are presented main matrix characteristics (LAMBDA) as well as their partial and cumulative contribution to clarify the general variability. The characteristic ranks are sorted by size and 12 matrix are obtained but valid according to the Hotteling method and GK criteria (Gutman-Kaiser), three main components have been extracted which together account for $63.60 \%$ of the variance of the entire motor and situational system. The first characteristic matrix of the system explains $42.512 \%$ of the overall variance. The second characteristic matrix explains $12.31 \%$ of the general variance. The third characteristic matrix explains $8.77 \%$ of the common variance of the motor and situational variables system. 
Table 5. The main matrix characteristic of basic and motor variables and situational

\begin{tabular}{cccccccc}
\hline Comp. & Total & $\begin{array}{c}\% \text { of } \\
\text { Varaianca }\end{array}$ & $\begin{array}{c}\text { Cumul. } \\
\%\end{array}$ & Total & $\begin{array}{c}\text { \% of } \\
\text { Variance }\end{array}$ & $\begin{array}{c}\text { Cumul. } \\
\%\end{array}$ & Total \\
\hline 1 & 5.101 & 42.512 & 42.512 & 5.101 & 42.512 & 42.512 & 5.043 \\
2 & 1.478 & 12.314 & 54.826 & 1.478 & 12.314 & 54.826 & 1.833 \\
3 & 1.053 & 8.776 & 63.602 & 1.053 & 8.776 & 63.602 & 1.089 \\
4 & .913 & 7.612 & 71.214 & & & & \\
5 & .761 & 6.340 & 77.554 & & & & \\
6 & .742 & 6.186 & 83.740 & & & & \\
7 & .568 & 4.729 & 88.469 & & & & \\
8 & .431 & 3.591 & 92.060 & & & & \\
9 & .402 & 3.353 & 95.413 & & & & \\
10 & .349 & 2.906 & 98.318 & & & & \\
11 & .171 & 1.427 & 99.745 & & & & \\
12 & .031 & .255 & 100.000 & & & & \\
\hline
\end{tabular}

Table 6 shows the matrix of three-factor components as well as variability communality. The first component is designed with high values MJUHIP-Jump high above the place .855 , MJUPSH- Jump from the place with the step height .868 , MJULEP-Jump length from the place .792 and MTTEST-TAgile test -847 which indicate the dimensions of the explosive and velocity force. While the other high values in this component are MMEDCH-Throwing the medicin ball from the chest .607, and MABDMU-Abdominal muscles .648 which provide knowledge of the explosive force of the hands and the abdominal muscle strength. From high-current situational motors are projected in the first and second component. In the first component is MBDBCZ-Ball dribble between cones (zigzag) -.798 and MBDSHO-Ball dribble and shooting in $30 \mathrm{sec}$ .509 whereas in the second component is MSHO2P-Shooting for 2 points .681 and MFRESH-Free shooting .763 all of them shows the speed with obstacles and accuracy of throwing in the basket. In the third component with the highest value was designed variable MPROAR-Profound warp (flexibility) .800 flexibility test. The value of communality for all variables ranges from .38 to .78 . Reliability for each variable depends on the size of the communality, respectively the uniqueness.

Table 6. Main Components and communality

\begin{tabular}{lcccc}
\hline variable & $\mathbf{1}$ & $\mathbf{2}$ & $\mathbf{3}$ & $\mathbf{H 2}$ \\
\hline MJUHIP & .855 & -.169 & -.005 & .760 \\
MJUPSH & .868 & -.180 & -.005 & .786 \\
MJULEP & .792 & -.228 & .022 & .680 \\
MSRU20 & -.660 & .258 & -.006 & .502 \\
MMEDCH & .607 & .059 & .107 & .383 \\
MPROAR & .218 & -.247 & .800 & .748 \\
MABDMU & .648 & .043 & -.447 & .622 \\
MTTEST & -.847 & -.029 & .074 & .723 \\
MBDBCZ & -.798 & -.117 & -.157 & .676 \\
MBDSHO & .509 & .413 & -.140 & .449 \\
MSHO2P & .125 & .681 & .390 & .632 \\
MFRESH & .298 & .763 & -.012 & .672 \\
\hline
\end{tabular}

Legend: MJUHIP-Jump high above the place; MJUPSH- Jump from the place with the step height; MJULEP-Jump length from the place; MSRU20-Speed running $20 \mathrm{~m}$ (higher start); MMEDCH-Throwing the medicin ball from the chest; MPROAR-Profound warp (flexibility); MABDMU-Abdominal muscles; MTTEST-T-Agile test; MBDBCZ-Ball dribble betweencones (zig-zag); MBDSHO-Ball dribble and shooting in $30 \mathrm{sec}$; MSHO2P-Shooting for 2 points; MFRESH-Free shooting

Table 7 on base of first matrix factor of parallel projections there are projected high-value variables which are expressing the explosive force of feet and hands, repetitive force, agility, and speed running with cofactors .561-.897, based on this projections this cofactor can be named as: propulsion factor of lower and upper extremities, repetitive force, agility.

In second factor of projections with higher values they have realized: Ball dribble and shoot on basket $30 \mathrm{sec}$, shoot for two points, and free shooting with cofactor .429-.790 this factor can be named as: the accuracy factor of throwing in the basket. The third high projection factor has achieved a single factor (Folding of the trunk before sitting), with cofactor 837 . This factor can be named as: factor of body flexibility.Showen the matrix of orthogonal projections of factor variables. The structure of this matrix does not change from matrix of parallel projections. 
Table 7. Matrix of parallel projections and orthogonal projections

\begin{tabular}{lcccccc}
\hline \multirow{2}{*}{ variable } & \multicolumn{2}{c}{ Matrix of parallel projections } & \multicolumn{3}{c}{ Matrix of orthogonal projections } \\
& $\mathbf{1}$ & $\mathbf{2}$ & $\mathbf{3}$ & $\mathbf{1}$ & $\mathbf{2}$ & $\mathbf{3}$ \\
\hline MJUHIP & .881 & -.055 & .035 & .869 & .118 & .016 \\
MJUPSH & .897 & -.064 & .038 & .883 & .112 & .019 \\
MJULEP & .837 & -.113 & .075 & .813 & .049 & .061 \\
MSRU20 & -.720 & .164 & -.066 & -.686 & .025 & -.058 \\
MMEDCH & .561 & .166 & .092 & .591 & .272 & .069 \\
MPROAR & .240 & .013 & .837 & .222 & .011 & .830 \\
MABDMU & .641 & -.001 & -.444 & .652 & .154 & -.460 \\
MTTEST & -.813 & -.117 & .076 & -.838 & -.283 & .104 \\
MBDBCZ & -.724 & -.262 & -.130 & -.773 & -.398 & -.096 \\
MBDSHO & .367 & .429 & -.228 & .458 & .516 & -.262 \\
MSHO2P & -.123 & .790 & .229 & .028 & .751 & .185 \\
MFRESH & .043 & .778 & -.182 & .203 & .798 & -.230 \\
\hline
\end{tabular}

In Table 8 the matrix intercorrelation of the moving factors it seems there is no significant correlation between them, and

the factors between them are independent of each other.

Table 8. Correlations between factors

\begin{tabular}{lccc}
\hline Comp. & Factor $\mathbf{1}$ & Factor 2 & Factor 3 \\
\hline Factor 1 & 1.000 & & \\
Factor 2 & .199 & 1.000 & \\
Factor 3 & -.025 & -.060 & 1.000 \\
\hline
\end{tabular}

Legend: Factor 1. Propulsion factor of lower and upper extremities, repetitive force, agility; Factor 2. The accuracy factor of throwing in the basket; Factor 3. Factor of body flexibility

\section{Discussion}

In this modest research is treated sample of basketball players which were evaluated in morphological characteristics, basic motor typical tests of basketball game. In the current research, in general, the same factors are extracted into the latent space. If we look at the research papers with research character in morphological characteristics we may see that some researches with search character we may compare them with our research paper. At the longitudinal factor of the skeleton, the other authors have reached to introduce into the latent space (Aruković, 2013) to Bosnian basketball players he has also extracted the same factor. In others authors researches (Hadzic et al., 2016), have had to paper-experiment with title analysis of morphological structure characteristics on new basketball players, in which they extracted the same factor as our research, in which they are determined for the longitudinal skeletal factor. Also the Croatian authors have extracted the same longitudinal skeleton factor (Trninić, Jeličić, \& Foretić, 2013). Other morphological latent dimensions are presented by authors (Šišić, Krespi, \& Pojskić, 2015) to Bosnian basketball players in which factor was extracted as the volume and body mass factor with $37 \%$ of the high correlation variance. In this area he applied the program to students on characteristics of basketball players in the factorial space in which the same factor was extracted with the authors from Bosnia and Herzegovina (Korjenić, Jelčić, Vučić, Elkaz, \& Varešlija, 2013). The basketball game takes place to win the game, respectively to achieve the most successful points in the basket because accuracy as a skill engine is sensible, but as a goal we also got to work-experiment authors (Daskalovski \& Naumovski, 2011) so in their work is extracted as the second factor the accuracy factor of the throw in the basket. The same factor of the typical accuracy of the basketball game is also extracted by the author (Kryeziu, 2016), the content of this factor suggests that a latent specific dimension type of basketball game, dealing with a latent specific dimension in the successful realization of the accuracy of the dribble and throw-in technique, the shot for two points from half-distance and free-throw for one point. Tests of propulsion forces of lower and upper extremities, of repetitive force and agility authors (Jukić et al., 2005) have had to do the work-experiment determining the latent structure of characteristics the process of preparation of basketball players in which are the main skills of basketball player in extracted factors in the latent space and which are typical actions during the basketball game, by which is extracted the factor of the propulsion force of the lower and upper extremities, the repetitive force, and the agility. Also in other researches we have the same factors presented as we have the case with the author (Šabotić, 2013), in this case it is suggested that the basketball game performance will be a good influence on the development of specific motor skills of basketball players. The other motor test was taken for study by the authors (Jukić et al., 2005) in which they had for the paper-experiment the determination of latent structure, the characteristics of preparation process of basketball players, the flexibility tests had static and dynamic space, in this case has extracted the body's flexibility factor as in our research. Also the authors (Kocić \& Antonijević, 2013) has had to paper-experiment the structure of motor skills in basketball game in which it has extracted the factor in the latent space. The resulting results may have an excuse or methodological approach applied to the latent structure research on morphological characteristics and the basic and typical situational motor testing of the basketball game, in particular we have a review of basketball players. 


\section{Acknowledgements}

The authors would like to thank young Tested teams of Mitrovica Region are: Basketball Club BC "Mitrovica", Basketball Club BC "Trepça" from Mitrovi$\mathrm{ca}$, and Basketball Club BC "Vushtriabasket" from Vushtrri. While the Pristina Region are those temas: Basketball Club BC "Collage Universi", Basketball Club BC "Fatosat", Basketball Club BC "Albabasket", and Basketball Club BC "Probasket" all those clubs from Pristina, basketball players team who voluntarily participated in this research.

\section{Conflict of Interest}

The authors declare that there are no conflicts of interest.

Received: 11 July 2018| Accepted: 29 August 2018| Published: 01 October 2018

\section{References}

Arukovic, Z. (2013). Canonical relations morphologic features, motor abilities and tests with sitacioni basketball players aged 12-14 years. Sport Mont, XI(37-38-39), 580-583.

Daskalovski, B. \& Naumovski, M. (2011). Latent structure on applied situational-motor variables at young basketball players from Republica of Macedonia. 1st International Conference on Sports Science and Health (305-313), Banja Luka.

Petrov, L. (2011). Specification of the motor potential structure of young basketball players in Bulgaria, Sportske Nauke i Zdravlje, 1, 58-63.

Jeličić, M. (2006). Morfološko-motorični potencijal in igralna učinkovitost mladih košarkarskih reprezentanc Slovenije. [Morphological-motor potential and playing efficiency of young basketball national teams of Slovenia. In Slovenian]. Unpublished Doctoral dissertation, University of Ljubljana. Ljubljana: Fakulteta za šport.

Jukić, I., Milanović, D., \& Vuleta, D.(2005). The latent structure of variables of sports preparation and athletic preparedness based on physical condictioning contents in basketball. Kinesiologica, 37(2), 182-194.

Hadzic, R., Vujović, D., Petković, J., Nikšić, E., \& Đukić, M. (2016). Analysis the structure of anthropometric characteristics with young basketball players. Sport and health, 3, 5-6.
Šišić, N., Krespi, M., \& Pojskić, H. (2015). Morfoloske latentne dimenzije kao predictor eksplozivnih manifestacija analiza na uzorku vrhunskih kosarkasaj uniora. 13. Godišnja međunarodna konferencija kondiciska prirema sportasa (75-78). Zagreb.

Sabotic, B. (2013). Canonical relations between basic and motor - situational-motor skills in sport games. Sport Mont, XI(37-38-39), 574-579.

Korjenić, A., Jelčić, M., Vučić, D., Elkaz, D., \& Varešlija, F. (2013). The effectivity of applied programme of work in choice classes of basketball on transformation morphologival status students of faculty of sport. 3rd Intern7ational Conference on Sports Science and Health (80-87). Banja Luka.

Kocic, J., \& Antonijevic, S. (2013). The structure of motor abilities in basketball players. Sport Mont, XI(37-38-39), 364-369.

Kryeziu, A. (2016). Factoral structure of basic motor and situational test of basketball players aged 14-15 years. 9. Medunarodni Kongres, Sport i zdravlje Zbornik Naucnih i Strucnih radova (202-207). Tuzla, Bosnia and Hercegovina.

Kryeziu, A. \& Asllani, I. (2016). The structure of morphological characteristics and basic motor skills of the typical game of basketball junior. European Journal of Health \& Science in Sports, 3(2), 7-10.

Trninić, S. (1996). Analiza i učenje košarkaške igre. [Analysis and learning of basketball game. In Croatian]. Pula: Vikta.

Trninić, S., Karalejić, M., Jakovljević, S., \& Jelaska, I. (2010). Structural Analysis of Knowledge Based on Principal Atributes of the Game of Basketball. Physical Culture, 64(1), 5-25.

Trninić, S., Karalejić, M., Jakovljević, S., \& Jelaska, I. (2010). Structural analysis of knowledge based on specific attributes of the game of basketball. Physical Culture, 64(2), 22-41.

Trninić, M., Jeličić, M., \& Foretić, N. (2013). The relations between the morphological status, situational efficiency and sport achievement of elite junior basketball teams. Fizička kultura, 66(2), 100-109. 